\title{
What can we learn from the January 2012 northern Italy earthquakes?
}

\author{
Marco Massa , Gabriele Ameri, Sara Lovati, Rodolfo Puglia, Gianlorenzo Franceschina, \\ Francesca Pacor, Lucia Luzi, Paolo Augliera
}

Istituto Nazionale di Geofisica e Vulcanologia, Sezione Milano-Pavia, Milan, Italy

\author{
Article history \\ Received February 16, 2012; accepted February 27, 2012. \\ Subject classification: \\ Ground motion, Waves and wave analysis, Data processing, Seismological data.
}

This note focuses on the ground motion recorded during the recent moderate earthquakes that occurred in the central part of northern Italy (Panel 1), a region that is characterized by low seismicity.

For this area, the Italian seismic hazard map [Stucchi et al. 2011] assigns a maximum horizontal acceleration (rock site) of up to $0.2 \mathrm{~g}$ ( $10 \%$ probability of being exceeded in 50 yr). In the last $4 \mathrm{yr}$, this region has been struck by 9 earthquakes in the magnitude range $4 \leq M_{w} \leq 5.0$, with the three largest located in the Northern Apennines (the $\mathrm{M}_{\mathrm{w}} 4.9$ and 5.0 Parma events, in December 2008 and January 2012) and on the Po Plain (the $M_{w} 4.9$ Reggio Emila event, in January 2012). We have analyzed the strong-motion data (distance $<300 \mathrm{~km}$ ) from these events as recorded by stations belonging to the Istituto Nazionale di Geofisica e Vulcanologia (RAIS, http:// rais.mi.ingv.it; RSNC, http:// iside.rm.ingv.it) and the Department of Civil Protection (RAN, www.protezionecivile.it; http://itaca.mi.ingv.it).

The 2008 and 2012 Parma events were both characterized by reverse focal mechanisms (http:/ / cnt.rm. ingvit/), with depths of $27 \mathrm{~km}$ and $60 \mathrm{~km}$, respectively. The deeper event produced a maximum peak ground acceleration (PGA) of $97 \mathrm{~cm} / \mathrm{s}^{2}$ at Novellara station (NVL, EC8 C class; $70 \mathrm{~km}$ from the epicenter). The January 25 , 2012, event had a depth of $34 \mathrm{~km}$ and produced a maximum PGA of $114 \mathrm{~cm} / \mathrm{s}^{2}$ at Sorbolo station (SRP; $7 \mathrm{~km}$ from the epicenter).

Preliminary analyses show the following:

1) Peculiar ground-motion attenuation of the deep Parma event with respect to the shallow event. In Panel 2, the PGAs for the two Parma events are plotted as functions of the hypocentral distance and compared with the global ground motion prediction equation (GMPE) calibrated by Cauzzi and Faccioli [2008] using events with depths $<30 \mathrm{~km}$. The different distance decays of the PGAs for the deep event (blue for A class of EC8, and red for B and C classes) [CEN 2003] are evident, in particular for distances up to $100 \mathrm{~km}$. On the other hand, the PGAs of the 2008 Parma crustal event (gray) are well explained by this GMPE.

In Panel 3, the PGAs for the deep 2012 event are grouped for the EC8 classes and are compared with the national GMPE calibrated by Bindi et al. [2011] using crustal events and epicentral distances. Also in this case, the GMPE underestimates the PGAs up to $200 \mathrm{~km}$. Although most of the class C sites (red) show the largest PGAs, the underestimation cannot be completely ascribed to site effects. The large PGAs from the Parma deep event, with respect to the shallow one, can be explained in terms of source effects (e.g. large stress-drop values that enhance the high-frequency radiation). In addition, as explained by Castro et al. [2008], the different attenuation in the lower and upper crust could explain the large PGAs recorded for the 2012 deep event.

2) Seismic amplification at the Po Plain sites. In Panel 4, the PGAs of the January 25, 2012, $\mathrm{M}_{\mathrm{w}}$ 4.9, Reggio Emilia event are plotted as a function of the epicentral distances, together with the Bindi et al. [2011] GMPE. In general, the largest amplitudes occur at the Po Plain sites (red), which suggests possible peculiar site responses. An overall increase in the PGAs is seen around $100 \mathrm{~km}$, in agreement with the results of Bragato et al. [2011], who studied the regional influence of Moho S-wave reflections in the area.

An example of the site response is shown in Panel 5. This considers the TREG (class C) and ZEN8 (class A) stations (Panel 5a), which are located at $88 \mathrm{~km}$ from the Reggio Emila epicenter. The rotational standard spectral ratio (Panel 5b) for $10 \mathrm{~s}$ of $\mathrm{S}$ waves shows polarized amplifications around $2 \mathrm{~Hz}$, which were also detected at other Po Plain sites (not shown), as well as amplification on the vertical component.

The points discussed above should to be interpreted as a warning for future applications dealing with groundmotion estimations in the aftermath of an earthquake in this area (e.g. ShakeMap calculation): the currently used GMPEs, which are based on different events and site characteristics, can lead to significant bias in the final results. 


\section{References}

Bindi, D., F. Pacor, L. Luzi, R. Puglia, M. Massa, G. Ameri and R. Paolucci (2011). Ground-motion prediction equations derived from the Italian strong motion database, B. Earthq. Eng., 9, 1899-1920.

Bragato, P.L., M. Sugan, P. Augliera, M. Massa, A. Vuan and A. Saraò (2011). Moho reflection effects in the Po Plain (northern Italy) observed from instrumental and intensity data, B. Seismol. Soc. Am., 101, 2142-2152.

Castro, R.R., M. Massa, P. Augliera and F. Pacor (2008). Bodywave attenuation in the region of Garda, Italy, PAGEOPH, 165, 1351-1366.

Cauzzi, C., and E. Faccioli (2008). Broadband (0.05 to $20 \mathrm{~s}$ ) prediction of displacement response spectra based on worldwide digital records, J. Seismol., 2, 453-475.

CEN (2003). prEN 1998-1-Eurocode 8: design of structures for earthquake resistance. P1: General rules, seismic actions and rules for buildings. Draft 6, Doc CEN/TC250/SC8/N335, Jan 2003, Brussels.

Stucchi, M, C. Meletti, V. Montaldo, H. Crowley, G.M. Calvi and E. Boschi (2011). Seismic hazard assessment (20032009) for the Italian building code, B. Seismol. Soc. Am., 101, 1885-1911.

\footnotetext{
^Corresponding author: Marco Massa, Istituto Nazionale di Geofisica e Vulcanologia, Sezione Milano-Pavia, Milan, Italy; email: marco.massa@mi.ingv.it. 

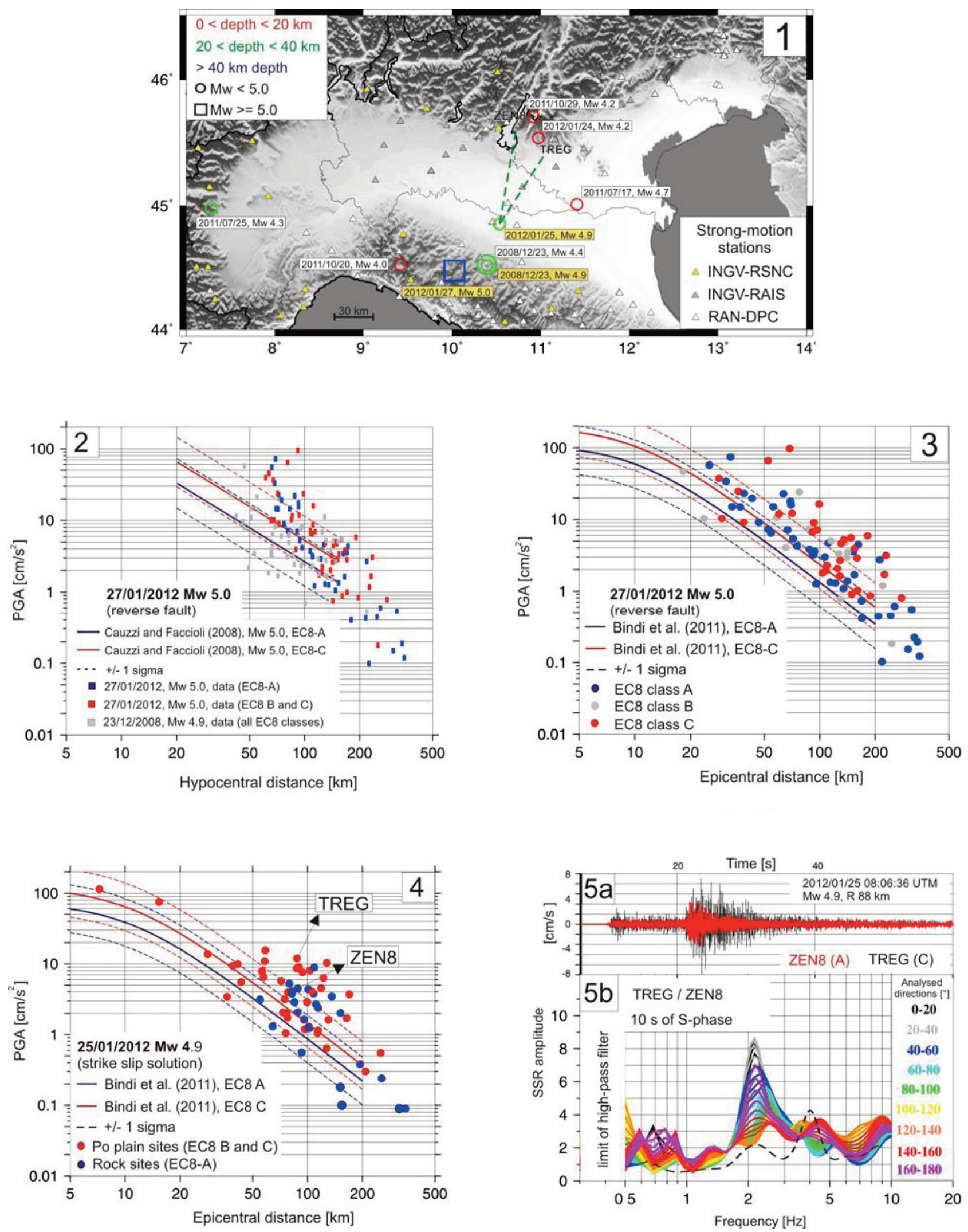

Panels. 1: Instrumental seismicity of the area from 2008 to $2012\left(\mathrm{M}_{\mathrm{w}} \geq 4\right.$, http://cnt.rm.ingvit/tdmt.html). Yellow insets, analyzed events. 2: Comparison between the PGAs recorded for the January 27, 2012, $\mathrm{M}_{\mathrm{w}}$ 5.0, event and the Cauzzi and Faccioli (2008) GMPE. Gray symbols, PGAs recorded for the 2008 Parma, $\mathrm{M}_{\mathrm{w}} 4.9$ event. 3: Comparison between the PGAs recorded for the January 27, 2012, $\mathrm{M}_{\mathrm{w}}$ 5.0, event and the Bindi et al. [2011] GMPE. 4: Comparison between the PGAs recorded for the January 25, 2012, $\mathrm{M}_{\mathrm{w}}$ 4.9, event and the Bindi et al. (2011) GMPE. 5a: NS component of the January 25, 2012, event $\left(\mathrm{M}_{\mathrm{w}} 4.9\right)$ as recorded at the TREG (C class) and ZEN8 (A class) RAIS stations. 5b: Rotational standard spectral ratio (SSR) calculated on $10 \mathrm{~s}$ of the S-phases for the January 25, 2012, $\mathrm{M}_{\mathrm{w}} 4.9$ event as recorded at the TREG station (with ZEN8 as reference). Dashed black line, vertical SSR. 